\title{
Age and Disability Employment Discrimination: Occupational Rehabilitation Implications
}

\author{
Melissa J. Bjelland $\cdot$ Susanne M. Bruyère • \\ Sarah von Schrader • Andrew J. Houtenville • \\ Antonio Ruiz-Quintanilla · Douglas A. Webber
}

Published online: 14 August 2009

(c) The Author(s) 2009. This article is published with open access at Springerlink.com

\begin{abstract}
Introduction As concerns grow that a thinning labor force due to retirement will lead to worker shortages, it becomes critical to support positive employment outcomes of groups who have been underutilized, specifically older workers and workers with disabilities. Better understanding perceived age and disability discrimination and their intersection can help rehabilitation specialists and employers address challenges expected as a result of
\end{abstract}

The research described in this paper is part of a larger study entitled Using the U.S. Equal Employment Opportunity Commission (EEOC) Employment Discrimination Charge Data System for Research and Dissemination Purposes funded by the U.S. Department of Education National Institute on Disability and Rehabilitation Research to Cornell University for a 3-year Field-Initiated Research Project (Grant No. H133G040265).

Melissa Bjelland and Susanne Bruyère have obtained Intergovernmental Personnel Act (IPA) positions at the EEOC, which have afforded them access to the EEOC's computerized data system which includes detailed information on every charge the EEOC receives, as well as those which are dually-filed with FEPAs. Further information about the IPA should be directed to Melissa Bjelland (Email: mjb62@cornell.edu). The statistics reported in these materials are derived from data files obtained under this agreement from the U.S. Equal Employment Opportunity Commission. The findings and their interpretation do not necessarily represent the policy of the Department of Education or the U.S. Equal Employment Opportunity Commission, and you should not assume endorsement by the Federal Government (Edgar, 75.620 (b)). Summaries of data are based on our aggregations and do not represent the EEOC's official aggregation of the data.

M. J. Bjelland · S. M. Bruyère $(\bowtie) \cdot S$. von Schrader Employment and Disability Institute, School of Industrial and Labor Relations, Cornell University, 201k Dolgen Hall, Ithaca, NY 14853-3901, USA

e-mail: smb23@cornell.edu the evolving workforce. Methods Using U.S. Equal Employment Opportunity Commission Integrated Mission System data, we investigate the nature of employment discrimination charges that cite the Americans with Disabilities Act or Age Discrimination in Employment Act individually or jointly. We focus on trends in joint filings over time and across categories of age, types of disabilities, and alleged discriminatory behavior. Results We find that employment discrimination claims that originate from older or disabled workers are concentrated within a subset of issues that include reasonable accommodation, retaliation, and termination. Age-related disabilities are more frequently referenced in joint cases than in the overall pool of ADA filings, while the psychiatric disorders are less often referenced in joint cases. When examining charges made by those protected under both the ADA and ADEA, results from a logit model indicate that in comparison to charges filed under the ADA alone, jointly-filed ADA/

\author{
M. J. Bjelland \\ e-mail:mjb62@cornell.edu \\ S. von Schrader \\ e-mail: sv282@cornell.edu
}

A. J. Houtenville

New Editions, McLean, VA, USA

e-mail: ahoutenville@neweditions.net

A. Ruiz-Quintanilla

Independent Consultant, Burdett, NY, USA

e-mail: drtonyruiz@gmail.com

D. A. Webber

Department of Economics, Cornell University, Ithaca, NY, USA

e-mail: daw225@cornell.edu 
ADEA charges are more likely to be filed by older individuals, by those who perceive discrimination in hiring and termination, and to originate from within the smallest firms. Conclusion In light of these findings, rehabilitation and workplace practices to maximize the hiring and retention of older workers and those with disabilities are discussed.

Keywords Americans with Disabilities Act · Age Discrimination in Employment Act - Disabled persons . Employment discrimination · Disability discrimination

\section{Introduction}

America's cohort of older workers is one of the fastest growing subsets of the workforce [1]. Its relative expansion translates into an increased number of age discrimination claims being filed with the Equal Employment Opportunity Commission, making it the fastest growing category of discrimination cases [2]. As the workforce ages it is necessary to enhance our understanding of how and when age interacts with other demographic characteristics of individuals to influence employment outcomes. In particular, because the incidence and prevalence of disability increase with age [3, 4], supporting the retention of older workers, including those with disabilities, who desire to remain productive members of the job pool of the future will become a challenge. For American businesses to address this, it is imperative that employers become knowledgeable about where discrimination is perceived to be occurring, and in turn, how to minimize discrimination toward and maximize the participation of both older workers and those with disabilities.

In this study, we examine age, disability, and joint age and disability related claims of employment discrimination, using data from the U.S. Equal Employment Opportunity Commission (EEOC) and state Fair Employment Practice Agencies (FEPAs) to inform our understanding of where older workers and people with disabilities perceive barriers in the employment experience. We begin by providing an overview of selected literature to document the growth of the aging workforce and identify challenges that we anticipate as a result. One of the primary challenges we see in the future is hiring and retaining older workers and workers with disabilities. To better understand the barriers to successful employment for these groups, we consider previous studies on causes and consequences of age and disability discrimination in the workplace. Subsequently, we present analyses of 15 years (1993-2007) of EEOC charge data filed under the Americans with Disabilities Act of 1990 (ADA) and the Age Discrimination in Employment Act of 1967 (ADEA), particularly focusing on charges filed jointly under both statutes. Title I of the ADA prohibits private employers, state and local governments, employment agencies and labor unions from discriminating against qualified individuals with disabilities in hiring and retention phases of employment; while the ADEA protects employees and job applicants who are 40 years of age or older from employment discrimination based on age. Finally, based on our analyses of discrimination charges filed under the ADA and ADEA, we discuss issues relevant to rehabilitation and human resource practitioners, including strategies to improve employment outcomes of older workers and those with disabilities and chronic health conditions.

\section{An Evolving Workforce}

The U.S. Bureau of Labor Statistics estimates that the number of workers 55 years and older is expected to increase by $47 \%$ during the period from 2006 to 2016 [1]. Their proportion of the total workforce is also growing, increasing from $11.9 \%$ in 1996 , to $16.8 \%$ in 2006 , to a projected $22.7 \%$ in 2016 [1]. Not everyone agrees on the business implications of such a large group of 55-64 yearolds in the workforce.

As Baby Boomers, born between 1946 and 1964 [5], age and enter retirement, the growth of the labor force is expected to slow significantly [1]. In the U.S., over four million already have left the workforce either because they are disabled or because they have retired [6]. Approximately one-half of the federal workforce will reach retirement age within the next 5 years [7]. This demographic trend is evident both in public and private sector American workplaces, causing some employers to express concern about a possible labor shortage [8]. The aging of the seasoned workforce and the related thinning labor pool due to retirement are anticipated to contribute to a talent shortage that will be characterized by a loss of institutional memory that is critical for the continued effectiveness of business organizations [7, 9].

Some feel that the workforce challenge of the future is not a shortage of workers, but the abundance of older workers who would like to retain employment. It is estimated that older workers will need the income that working longer will provide in order to fund their retirement [10]. A survey of American workers conducted in the spring of 2005 reported that nearly a quarter said that they would be working either full-time or part-time for needed income following retirement, compared with only $13 \% 5$ years earlier [11]. The American Association of Retired Persons (AARP) recently found that $27 \%$ of respondents ages 55-64 are postponing plans to retire [12]. This trend is also demonstrated in labor force participation rates of workers 55 and older increasing from $30.3 \%$ in 1996 to $38.0 \%$ in 2006, with this rate anticipated to increase to $42.8 \%$ by 2016 [1]. 
Retaining older workers may be in the best interest of the individual as well as the organization. However, the abundance of conflicting information on the costs to a firm of employing older workers may forestall any immediate solutions $[13,14]$. A number of studies examine the impact of the aging process on the occurrence of disability and the resulting impact on employability and performance in the workplace. Some studies claim that as workers age, they have more difficulty performing physical tasks and are more susceptible to injury [15, 16]. Results of research conducted in three states using administrative data on workers' compensation claims linked to longitudinal earnings records suggest that older workers are more likely than their younger counterparts to have permanent disabilities as a result of work-related injuries. This is true even though the older workers reportedly have fewer workplace accidents [17].

The prevalence of disability increases substantially with age. While $10 \%$ of adults younger than 40 report a work limiting disability, this grows to one-quarter of 60 yearolds and one-third of 65 year-olds [4]. Research by Platt [18] indicates that by the age of 50, a person's first serious medical problem will occur, with a $25 \%$ chance that it will be a life-long condition. He emphasizes the importance of return-to-work or disability management initiatives for Baby Boomers, predicting that without this the cost of short- and long-term disability as well as workers' compensation will escalate. The primary emphasis of disability management when applied in the employment setting is preventing or minimizing the impact of the disability on the employer and employee and assisting in job retention for the disabled/injured [19, 20].

Concern persists about stimulating the hiring and retention of people of all ages with disabilities. People with disabilities represented $12.8 \%$ of the U.S. workingage population in 2007 [21]. Despite this, they remain a significantly underutilized labor source due to disproportionate disadvantages in gaining equal access to employment and subsequent economic self-sufficiency. The employment rate of working-age people with disabilities was $36.9 \%$ in 2007 , compared with $79.7 \%$ for workingage people without disabilities - an employment gap of $42.8 \%$ points [21]. The difference in the median earnings between working-age people with and without disabilities who worked full-time/full-year was \$6,500 [21]. Even when controlling for educational attainment, disabled workers are substantially overrepresented in highly physical, entry level, and low skill occupations, those occupations that pay the lowest wages and are most vulnerable to job losses [22]. The relative economic well-being of working-age people with disabilities is declining, and this has prompted initiatives to consider innovative methods to improve supports for people with disabilities and evaluate whether any significant policy reforms should be pursued [23].

Toward Understanding Discrimination in the Workplace

There is evidence that there will be a greater number of older people, and therefore a higher prevalence of disability, in the workforce in the coming years due to workforce needs and the desire of workers to stay in the workforce longer. Unfortunately, the mature workforce and workers with disabilities are too often seen as a problem to be dealt with, rather than a workforce opportunity which can be leveraged [7]. In order to take full advantage of the resources of these groups, it is crucial that every effort is made to understand and eliminate discrimination in the workplace.

The issue of age discrimination in employment is not new, and significant research has been conducted to date to examine the ensuing problems. This research suggests that employers discriminate against older workers during the job application process [24, 25]. Once on the job, age discrimination is prevalent and impacts the job security, deployment, retention, and promotion of older workers [26].

Perry and Parlamis [27] conducted a review of age and ageism in organizations. The literature that they reviewed suggested that people often hold negative and inaccurate beliefs about older workers. While stereotyping does not imply discriminatory treatment, the two often go hand in hand [26]. Common negative stereotypes about older workers are that they do not perform as well, are less trainable, more resistant to change, less economically beneficial, more costly, and a poorer return on investment as compared with younger workers. The various stereotypes that younger workers have of their older peers can greatly influence workplace dynamics [14]. Some common stereotypes of older workers such as poor performance and shorter tenure have been refuted by a body of research showing that performance tends to improve with age and that older workers are less likely to quit [28]. Unfortunately, stereotypes continue to be pervasive [29], and such perceptions have clearly had an influence on older workers' (particularly men's) labor force participation rates in the past [30, 31]. Ineffective management of the aging workforce and a non-accommodating environment may contribute to claims of discrimination.

In comparison to age discrimination, there have been fewer studies of disability employment discrimination [26]. In a review of research, Stone-Romero, Stone, and Lukaszewski [32] found that employers are concerned that people with disabilities are less skilled, require more supervision, increase health care costs, and have low levels of emotional adjustment. Again, while negative attitudes 
and stereotyping do not imply discrimination, when such attitudes are present, they are likely to color the work experiences of people with disabilities. In another study regarding attitudes toward people with disabilities, a survey of human resources professionals in both the private and federal sectors found that lack of requisite work experience, skills and training, supervisor lack of knowledge about accommodations, and supervisor or coworker attitudes were key barriers to employment and advancement for people with reported disabilities [33]. These findings are similar among different-sized organizations and across cultures [34, 35]. Discrimination is cited as a likely reason for the poorer employment outcomes (e.g., lower employment rates, lower earnings, poorer representation in skilled occupations) of people with disabilities [22].

It is important to assess which parts of the employment process and which types of chronic health or disabilityrelated issues are most likely to result in claims of employment discrimination. If we have better understanding of these aspects of perceived discrimination, it will be easier to target initiatives to improve workplace environments. The subsequent analyses of employment-related discrimination charges aim to shed light on where and how disability and age-related employment discrimination is perceived to be occurring.

\section{Methods}

To investigate charges filed under the ADA and the ADEA from 1993 to 2007, we use data from the EEOC's Integrated Mission System (IMS). Since 1991, the EEOC has collected integrated data on individual charges and allegations filed in both EEOC and FEPA offices into a national computerized and standardized database. We use two data files extracted from this system, the charge and allegation files. The former dataset contains information unique to each charge of discrimination that is filed. The latter describes every allegation associated with each charge, where an allegation is based upon the combination of statute, basis (i.e., trait upon which discrimination is based), and issue (i.e., discriminatory behavior). In integrating these files, we retain a single record per charge to permit the identification of those charges that cite multiple statutes, bases, or issues. This merged dataset contains information about the charging and charged parties, and case-related details.

The main variable of analysis is the number of charges filed, in particular, all ADA and ADEA charges filed alone or jointly under other statutes. We evaluate patterns in charges over several independent variables, including year of intake, charging party's age, as well as the bases and issues cited. Year of intake and the charging party's age allow us to describe trends over time and across the age spectrum, respectively. We use bases and issues to characterize the nature of the charge-the type of disability upon which the charge is based and the alleged discriminatory action, or issue.

We use charges filed with the EEOC and FEPA from the beginning of fiscal year 1993 to the end of fiscal year 2007. Data prior to 1993 is excluded because the implementation of the ADA employment provisions started July 26, 1992, making only a portion of that fiscal year's (October 1-September 30) information available. A total of 16,913 charges that do not specify at least one basis, issue, and statute or that were filed outside the 50 states and the District of Columbia are excluded from analysis. The EEOC IMS file is corrected for erroneous or missing statute data using basis whenever possible. For the other charging party and alleged discriminating employer variables we analyze (i.e., age, gender, race, industry, and number of employers) we retain all observations but construct an indicator to flag when these fields are missing. The categories presented in our analyses include ADA alone or jointly, which includes all retained ADA claims in the EEOC database, including those that were filed under multiple statues (other statues include: Title VII of the Civil Rights Act and the ADEA). The ADA alone category are charges that were filed only under the ADA. Likewise, the interpretations of the categories ADEA alone or jointly and ADEA alone are similar. Because age is an important variable in our analyses, it should be noted that there are more missing age data for ADA charges than for ADEA charges. Among all charges in the database, 24.1 and $20.5 \%$ are missing age for ADA alone or jointly and ADA alone, respectively. The percent of all charges for the ADEA and ADA/ADEA filed jointly that are missing age is between 2.2 and $3.7 \%$. The final database used for analysis contains 2,147,017 charges filed from 1993-2007, of those charges 462,956 were filed under the ADA alone or jointly, 308,998 under the ADA alone, 427,525 under the ADEA alone or jointly, 227,327 under the ADEA alone, and 68,569 jointly under the ADA/ ADEA.

We use descriptive statistics to analyze patterns and trends. When comparing across issues and bases, we examine the most frequently cited issues and bases. As an extension, we use a logit estimation to evaluate the manner in which charge characteristics influence the decision to jointly file ADA/ADEA complaints.

\section{Results}

Time Trends

Using the EEOC IMS data, we investigate the trends in discrimination claims across the aging and disability 
Fig. 1 Number of charges filed per 10,000 labor force participants in each protected class by statute, 1993-2007

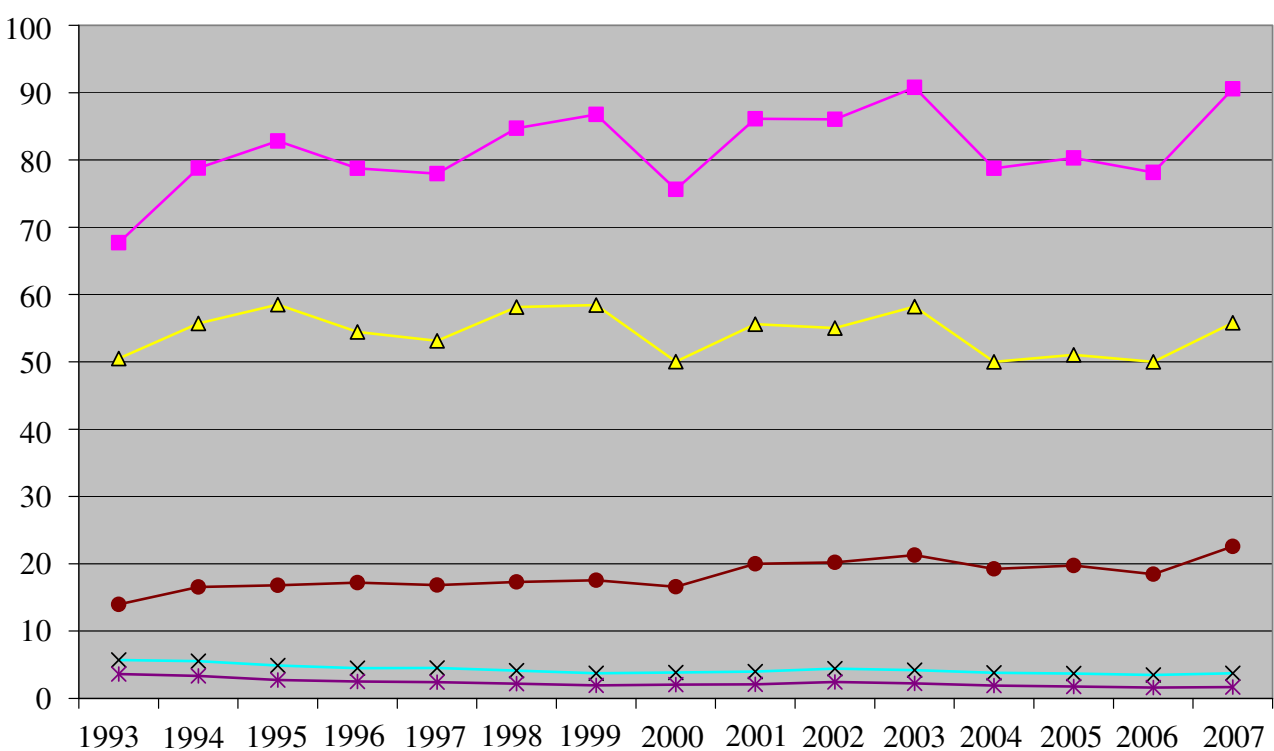

- ADA $\triangle$ ADA Alone $\rightarrow$ ADEA $*$ ADEA Alone $\rightarrow-$ Joint ADA/ADEA populations. Figure 1 presents labor force adjusted charges (charges per 10,000 people in the labor force in the protected class) filed under the ADA alone or jointly, ADA filed jointly, ADEA alone or jointly, ADEA filed jointly, and ADA/ADEA filed jointly. Data from the Annual Social and Economic Supplement to the Current Population Survey (CPS ASEC) for 1993-2007 are utilized to calculate these rates. The base population of disabled labor force participants in each year is identified using the work limitation question in the CPS ASEC.

As Fig. 1 indicates, ADA, ADEA, and jointly-filed ADA/ADEA charges per 10,000 people in the labor force follow unique patterns. Far more labor force participants who are disabled allege discrimination than do those who are 40 or older. Over the 15 year period, there are an annual average of 81.6 labor-force adjusted charges under the ADA (alone or jointly) and compared with 4.3 for the ADEA (alone or jointly). Among the protected class of people who are disabled and 40 or older, the equivalent average number of filings that reference both the ADA and ADEA is 18.3 .

Figure 1 informs us that the labor force-adjusted ADEA charges exhibit a slight decline over the course of the study. Meanwhile, the number of ADA and jointly-filed ADA/ADEA charges gradually rises over the years.

\section{Incidence by Age}

The percentage (averaged over the 15-year period 1993 2007) of ADA, ADEA, and jointly-filed ADA/ADEA charges across the age spectrum are presented in Table 1 . Our results indicate that disability claims increase in subsequent age groups up to a point. The pattern in claims by age group appears to mirror the pattern of increasing disability prevalence with age [3]. However, our sample restriction to labor force participants appears to contribute to the equally sharp decrease in the prevalence of ADA charges of discrimination for older cohorts. The exit of people with disabilities, relative to others, from the labor force as they age may cause the share of filings citing the ADA to decline with age.

The most interesting feature of the ADEA charges is the tendency for the younger cohorts to file alone and the older age groups to file jointly under other statutes, which is the reverse of the behavior observed in charges filed under the ADA.

It is clear that the older age groups represent a large proportion of the charges under each type of employment discrimination legislation examined in this study (see Table 1). Nearly $60 \%$ of ADA charges filed alone that report age are filed by individuals over 40 years old. Eighty percent of ADEA charges and $72 \%$ of ADA/ADEA jointlyfiled charges are submitted by those ages 50 and over.

\section{Incidence by Issue}

People file employment discrimination charges founded upon an event, or issue. Although there may be similarities across various pieces of anti-discrimination legislation where the ADA and ADEA are concerned, certain events (perceived discrimination during the employment process) are more likely to be based on age than disability. For example, our review of the literature suggests that hiring practices might result in a higher incidence of claims from 
Table 1 Percentage of charges filed by age group and statute, 1993-2007 average

\begin{tabular}{|c|c|c|c|c|c|}
\hline \multirow[t]{2}{*}{ Age group } & \multicolumn{2}{|l|}{ ADA } & \multicolumn{2}{|l|}{ ADEA } & \multirow{2}{*}{$\begin{array}{l}\text { ADA/ADEA } \\
\text { Filed jointly }\end{array}$} \\
\hline & Filed alone or jointly & Filed alone & Filed alone or jointly & Filed alone & \\
\hline $16-24$ & 4.60 & 3.69 & - & - & - \\
\hline $25-29$ & 8.10 & 6.79 & - & - & - \\
\hline $30-34$ & 12.72 & 10.89 & - & - & - \\
\hline $35-39$ & 17.09 & 14.60 & - & - & - \\
\hline $40-44$ & 18.54 & 17.19 & 6.50 & 9.26 & 9.65 \\
\hline $45-49$ & 16.81 & 16.73 & 13.40 & 16.83 & 17.89 \\
\hline $50-54$ & 11.95 & 13.88 & 21.56 & 23.55 & 25.23 \\
\hline $55-59$ & 6.70 & 9.27 & 24.29 & 22.98 & 23.32 \\
\hline $60-64$ & 2.47 & 4.61 & 20.27 & 16.86 & 15.39 \\
\hline $65-69$ & 0.66 & 1.45 & 8.18 & 6.33 & 5.26 \\
\hline $70+$ & 0.37 & 0.89 & 5.81 & 4.17 & 3.26 \\
\hline Missing & 24.13 & 20.50 & 3.73 & 3.09 & 2.22 \\
\hline
\end{tabular}

Source: Calculations by Cornell University, Employment and Disability Institute, using the EEOC IMS files, 1993-2007

older workers who have been discriminated against during the job application process [24, 25]. Our results confirm that those filing under the ADEA cite hiring more often than those who file under the ADA (15.5 vs. 9.1\%).

Figure 2 presents the percentage of charges filed under the ADA, ADEA and ADA/ADEA jointly that cite common issues. The five most common issues in ADA and joint ADA/ADEA filings are: discharge, terms/conditions of employment, reasonable accommodation, harassment, and hiring. Promotion is among the top five issues under the ADEA, since individual ADEA cases cannot cite reasonable accommodation. Charges of age discrimination filed with the EEOC involve discharge more often than any other action (48.7\%), as do disability-related charges $(55.7 \%)$ supporting the findings of previous studies [36, 37]. Our research also reveals that discharge is the most often cited issue in ADA/ADEA cases (55.7\%). Previous analyses of discrimination claims have shown that discharge is the most common issue across all civil rights employment laws that target specific classes of individuals [26]. Table 4 in the Appendix provides additional details regarding the relationship between issues and statutes.

Incidence by Basis

ADA charges are delineated by the disability type, or basis. Figure 3 illustrates the prevalence of cases for ten of the most-often cited specific disabilities over the 15-year period, 1993-2007. For purposes of comparison, shares of these bases for ADA charges filed alone are also presented. While the most commonly-cited bases in jointly-filed age and disability charges are other disabilities (26.7\% of all ADA/ADEA jointly-filed cases and $24.8 \%$ of all ADA cases filed alone), retaliation (17.3 and 7.6\%, respectively), and regarded as disabled (11.7 and 9.6\%, respectively), Fig. 3 presents only the most commonly cited specific disabilities (a complete list of bases cited is presented in Table 5 in the Appendix). As might be expected, the EEOC IMS data reflect higher proportions of charges for disabilities that are most prevalent. Among disabled worker beneficiaries of Social Security Disability Insurance, the most prevalent disabilities are mental disorders $(33.4 \%)$ and musculoskeletal disabilities $(25.9 \%)$; these are also the most common bases for charges under the ADA [38].

The difference between the profile of ADA complaints and joint ADA/ADEA charges is significant. Of note is the fact that age-related disabilities are more frequently referenced in joint cases than in the overall pool of ADA filings while the prevalence of psychiatric disorders, including depression, is diminished. This disparity between jointlyfiled ADA/ADEA and ADA charges is particularly striking among: heart/cardiovascular (8.3\% compared with $2.9 \%)$, diabetes $(5.1 \%$ compared with $3.6 \%)$ and cancer $(4.1 \%$ compared with $2.3 \%$ ). The relatively high number of charges for these health conditions among ADA/ADEA claimants is consistent with the fact that the likelihood of onset of these health conditions increases with age [3]. Interestingly, while the prevalence of musculoskeletal disabilities and vision/hearing impairments increases with age, the proportions of charges filed for orthopedic/structural back, hearing, and vision impairments are similar or higher under ADA alone as compared with ADA/ADEA filed jointly.

Certain parts of the employment process may be more problematic for employers, particularly where older workers are concerned [39]. Our analyses found that employment discrimination claims that originate from older workers and those with disabilities appear to be concentrated within a 


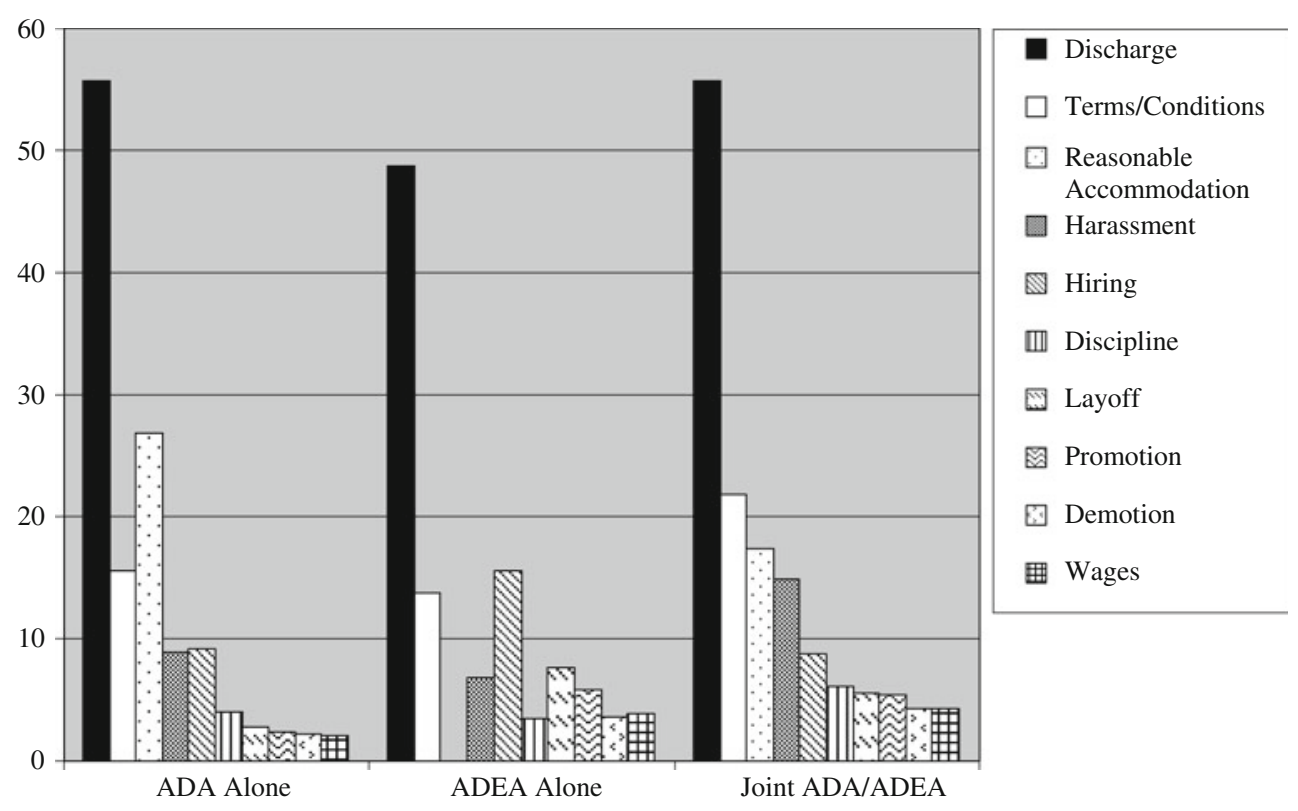

Fig. 2 Percentage of charges filed by statute (top joint issues), 1993-2007 average

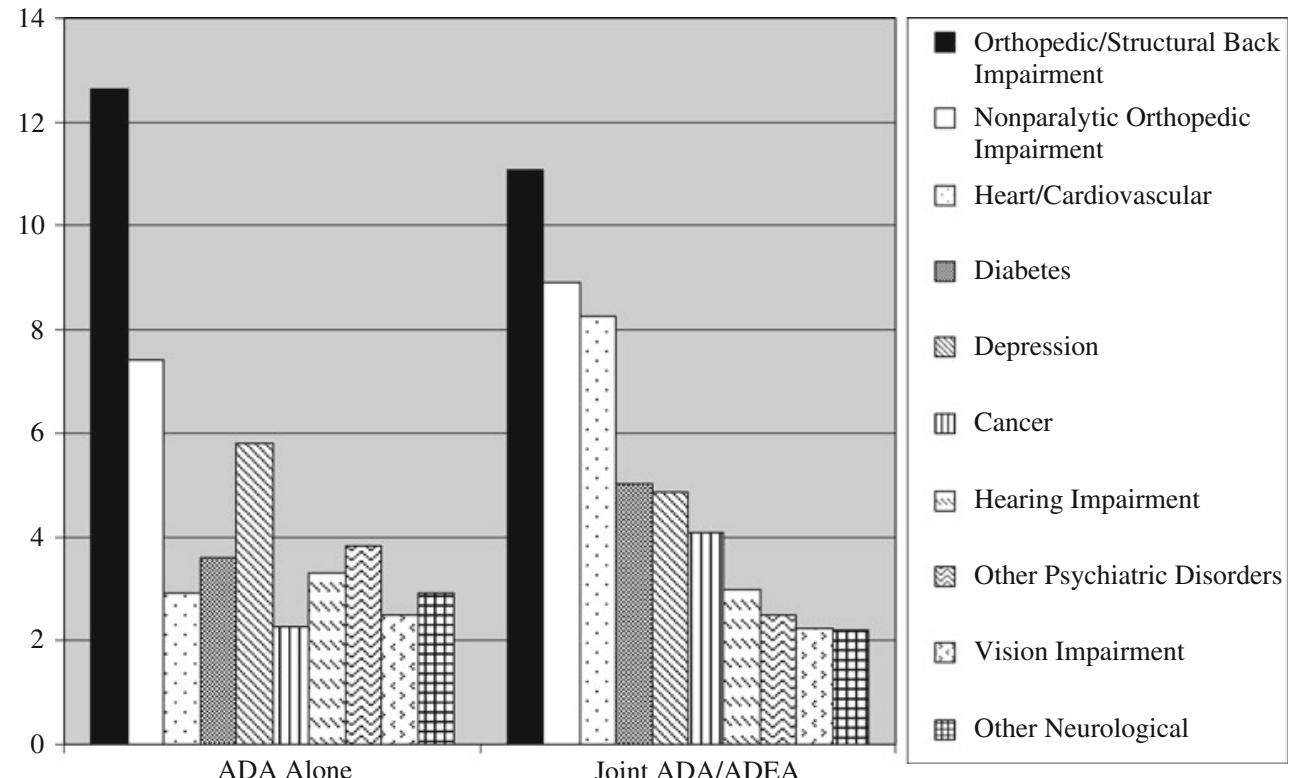

Fig. 3 Percentage of charges filed by statute (top joint bases), 1993-2007 average

subset of issues that include reasonable accommodation, termination, and also workplace retaliation as a basis. When looking separately at charges associated with each of these issues, we found the same pattern established earlier when examining bases by statute in Fig. 3: some age-related disabilities, such as diabetes, heart conditions and cancer, have a greater share of the reasonable accommodation, termination and retaliation caseload in joint ADA/ADEA charges in comparison to ADA alone charges. However, not all age-related disabilities are cited more often jointly, exceptions include hearing/vision and musculoskeletal conditions.

\section{Logit Analysis of Jointly-Filed ADA/ADEA Charges}

The statistics we have presented thus far summarize EEOC IMS data trends. More rigorous analysis is required to soundly interpret characteristic differences that may induce jointly-filed ADA/ADEA claims of discrimination. This analysis uses only charges made by those 40 and over with 
a disability (those protected by both the ADEA and ADA), and is intended to illuminate characteristics and circumstances that may lead an individual to feel "doubly" discriminated against, that is, file jointly under age and disability protections rather than disability alone. For this purpose, we implement a logit model to explore whether, relative to all individually-filed ADA claims, the jointlyfiled ADA/ADEA charges are more or less likely to be filed by people citing specific issues, or by those in certain age, race, or gender groups. Additionally, we compare the manner in which the likelihood of filing an ADA/ADEA joint charge of discrimination is affected by the industry and size of the employer. A total of 208,421 charges made under the ADA alone and 68,569 charges made jointly under the ADA and ADEA were included in this analysis.

The logit equation that we estimate is given by:

$y_{\mathrm{it}}=\alpha_{0}+\beta_{0} X_{\mathrm{it}}+\varepsilon_{\mathrm{it}}$,

where

$y_{\mathrm{it}}=1$, if individual $i$ files a joint ADA/ADEA charge,

0 , if individual $i$ files an ADA charge alone.

In this model, we incorporate the EEOC IMS variables described in Table 2. The sample consists of all people who filed an ADA claim either alone or in conjunction with the ADEA and are 40 or older or did not report their age. Among the covariates are indicator variables for commonly cited issues, these include: demotion, discipline, harassment, hiring, promotion, reasonable accommodation, terms/ conditions of employment, wages, and termination. The indicator variable for termination combines issues of constructive discharge, discharge, layoff, and involuntary retirement. The charging party's demographic variables are complemented by the Standard Industrial Classification (SIC) division, workforce size of the alleged discriminating employer, and geographic divisions defined by the US Census. While Eq. 1 contains year fixed effects, these effects are not reported in the results.

Odds ratios and the corresponding 95\% confidence intervals from the logit estimation are presented in Table 3. These odd ratios show the odds of jointly-filing charges of discrimination for people with a given characteristic as compared with those in the reference group (omitted group) controlling for other variables in the model; to interpret the odds ratios in terms of percent change, subtract one from the value of the odds ratio. The odds ratios inform us that demotion, harassment, hiring and termination-related events increase the likelihood of jointly filing by more than two times, while concerns about reasonable accommodation reduce the probability of jointly citing the ADA and ADEA by 52\%. Those citing promotion are substantially (over 3.6 times) more likely to submit a joint claim, while discipline increases the probability of joint ADA/ADEA claims by a comparatively moderate $57 \%$.

Men are almost $8 \%$ more likely than women to file claims jointly, while nonwhites are $35 \%$ more likely than whites to do so. Age appears to be strongly related the decision to cite jointly. Relative to those who are 40-44 years of age, each sequential cohort has an even higher likelihood of jointly filing. Interestingly, charges are more likely to be jointly filed when they originate from the smallest firms (the omitted group, comprised of 15 or fewer employees). The tendency to submit joint ADA/ADEA filings is reduced by between 30 and $38 \%$ among larger employers when compared with the smallest employer. Only in the industry of mining are claimants influenced in how they file: those in mining are $26 \%$ more likely than the omitted group (manufacturing) to jointly file under the ADA and ADEA.

Interestingly, when the logit analysis was replicated individually for the top six specific bases of jointly-filed claims (orthopedic/structural back impairment, nonparalytic orthopedic impairment, heart/cardiovascular, diabetes, depression, and cancer), the results were highly consistent with those of the overall regression presented in Table 3. Because of their similarity to the overall analyses, these results are not presented.

\section{Discussion}

The results of the analyses of the EEOC IMS data demonstrate that perceived employment discrimination is a problem, with many claims filed annually charging age and disability discrimination. Taking into account the number of people in the respective protected classes of the ADA and ADEA, there is a striking difference in the rate of charges under these legislations. People with disabilities are charging discrimination at a much higher rate, 81.6 ADA claims per 10,000 people in the protected class (people who are disabled) compared with 4.3 ADEA claims per 10,000 people in the protected class (40 and over). And unfortunately, labor-force adjusted charges filed under the ADA (alone or jointly) have remained relatively constant over the period from 1993-2007 (see Fig. 1). Even though the rate of complaints for age discrimination is relatively low compared with disability discrimination, it seems likely that the number of members of both of these protected classes (those 40 and older and people who are disabled) will grow in the coming years. Both the participation rate of older workers and the relative share of older workers in the workforce is expected to increase, and with those older workers there will likely be a higher prevalence of disability. If these groups grow, it becomes increasingly important to understand perceived discrimination in the 
Table 2 Descriptive statistics for logit analysis of jointly-filed ADA/ADEA charges

\begin{tabular}{|c|c|c|c|c|}
\hline \multirow[t]{2}{*}{ Variable } & \multicolumn{2}{|c|}{ ADA alone } & \multicolumn{2}{|c|}{ Joint ADA/ADEA } \\
\hline & Mean & SD & Mean & $\mathrm{SD}$ \\
\hline \multicolumn{5}{|l|}{ Age } \\
\hline $40-44$ & 0.210 & 0.407 & 0.093 & 0.290 \\
\hline $45-49$ & 0.188 & 0.391 & 0.173 & 0.378 \\
\hline $50-54$ & 0.133 & 0.339 & 0.246 & 0.431 \\
\hline $55-59$ & 0.074 & 0.262 & 0.229 & 0.420 \\
\hline $60-64$ & 0.027 & 0.163 & 0.152 & 0.359 \\
\hline $65-69$ & 0.007 & 0.085 & 0.052 & 0.222 \\
\hline $70+$ & 0.004 & 0.063 & 0.033 & 0.179 \\
\hline Missing & 0.357 & 0.479 & 0.022 & 0.146 \\
\hline \multicolumn{5}{|l|}{ Gender } \\
\hline Male & 0.502 & 0.500 & 0.539 & 0.498 \\
\hline Missing gender & 0.069 & 0.253 & 0.036 & 0.185 \\
\hline \multicolumn{5}{|l|}{ Race } \\
\hline Nonwhite & 0.280 & 0.449 & 0.270 & 0.444 \\
\hline Missing race & 0.198 & 0.398 & 0.131 & 0.337 \\
\hline \multicolumn{5}{|l|}{ Issue } \\
\hline Termination & 0.603 & 0.489 & 0.675 & 0.468 \\
\hline Reasonable accommodation & 0.270 & 0.444 & 0.177 & 0.381 \\
\hline Terms/conditions & 0.162 & 0.368 & 0.235 & 0.424 \\
\hline Harassment & 0.087 & 0.282 & 0.161 & 0.368 \\
\hline Hiring & 0.083 & 0.276 & 0.089 & 0.284 \\
\hline Discipline & 0.039 & 0.195 & 0.068 & 0.251 \\
\hline Promotion & 0.022 & 0.148 & 0.057 & 0.232 \\
\hline Demotion & 0.023 & 0.149 & 0.045 & 0.207 \\
\hline Wages & 0.021 & 0.143 & 0.046 & 0.210 \\
\hline \multicolumn{5}{|l|}{ Industry } \\
\hline Agriculture, forestry, fishing & 0.005 & 0.074 & 0.006 & 0.076 \\
\hline Mining & 0.005 & 0.070 & 0.006 & 0.077 \\
\hline Construction & 0.018 & 0.132 & 0.018 & 0.131 \\
\hline Manufacturing & 0.125 & 0.331 & 0.126 & 0.332 \\
\hline Trans., Comm., Elec., gas, and sanitary & 0.065 & 0.247 & 0.066 & 0.247 \\
\hline Wholesale trade & 0.016 & 0.127 & 0.017 & 0.129 \\
\hline Retail trade & 0.115 & 0.319 & 0.117 & 0.321 \\
\hline FIRE & 0.049 & 0.215 & 0.049 & 0.215 \\
\hline Services & 0.284 & 0.451 & 0.286 & 0.452 \\
\hline Public administration & 0.079 & 0.270 & 0.074 & 0.262 \\
\hline Missing industry & 0.238 & 0.426 & 0.237 & 0.425 \\
\hline \multicolumn{5}{|l|}{ Number of employees } \\
\hline$<15$ employees & 0.004 & 0.061 & 0.004 & 0.060 \\
\hline 15-100 employees & 0.316 & 0.465 & 0.322 & 0.467 \\
\hline 101-200 employees & 0.078 & 0.268 & 0.090 & 0.286 \\
\hline 201-500 employees & 0.080 & 0.272 & 0.093 & 0.291 \\
\hline $500+$ employees & 0.291 & 0.454 & 0.331 & 0.471 \\
\hline Missing number of employees & 0.232 & 0.422 & 0.159 & 0.366 \\
\hline \multicolumn{5}{|l|}{ Geographic region } \\
\hline New England & 0.073 & 0.259 & 0.050 & 0.218 \\
\hline Middle Atlantic & 0.144 & 0.351 & 0.129 & 0.335 \\
\hline East North Central & 0.210 & 0.407 & 0.206 & 0.404 \\
\hline
\end{tabular}


Table 2 continued

\begin{tabular}{|c|c|c|c|c|}
\hline \multirow[t]{2}{*}{ Variable } & \multicolumn{2}{|c|}{ ADA alone } & \multicolumn{2}{|c|}{ Joint ADA/ADEA } \\
\hline & Mean & SD & Mean & SD \\
\hline West North Central & 0.081 & 0.273 & 0.098 & 0.297 \\
\hline South Atlantic & 0.148 & 0.355 & 0.159 & 0.366 \\
\hline East South Central & 0.043 & 0.202 & 0.054 & 0.227 \\
\hline West South Central & 0.084 & 0.278 & 0.114 & 0.318 \\
\hline Mountain & 0.076 & 0.265 & 0.089 & 0.285 \\
\hline Pacific & 0.142 & 0.349 & 0.101 & 0.301 \\
\hline \multicolumn{5}{|l|}{ Year of filing } \\
\hline 1993 & 0.064 & 0.245 & 0.047 & 0.212 \\
\hline 1994 & 0.066 & 0.249 & 0.059 & 0.236 \\
\hline 1995 & 0.072 & 0.258 & 0.062 & 0.241 \\
\hline 1996 & 0.066 & 0.248 & 0.063 & 0.242 \\
\hline 1997 & 0.070 & 0.254 & 0.067 & 0.251 \\
\hline 1998 & 0.070 & 0.255 & 0.064 & 0.245 \\
\hline 1999 & 0.068 & 0.252 & 0.062 & 0.241 \\
\hline 2000 & 0.064 & 0.244 & 0.061 & 0.240 \\
\hline 2001 & 0.065 & 0.247 & 0.071 & 0.257 \\
\hline 2002 & 0.065 & 0.247 & 0.071 & 0.257 \\
\hline 2003 & 0.068 & 0.252 & 0.073 & 0.260 \\
\hline 2004 & 0.064 & 0.244 & 0.072 & 0.259 \\
\hline 2005 & 0.063 & 0.243 & 0.071 & 0.258 \\
\hline 2006 & 0.065 & 0.247 & 0.072 & 0.258 \\
\hline 2007 & 0.071 & 0.256 & 0.084 & 0.277 \\
\hline Observations & 208,421 & & 68,569 & \\
\hline
\end{tabular}

workplace. The following discussion highlights how we can use information gleaned from analysis of the ADA, ADEA and jointly-filed charges to inform the practices of rehabilitation professionals and employers.

Our analyses indicate that discrimination claims are common among older age groups. Nearly $60 \%$ of ADA charges (that report age) are filed by individuals over 40 years old, which is the protected age group under the ADEA. Eighty percent of ADEA charges and $72 \%$ of ADA/ ADEA jointly-filed charges are submitted by those ages 50 and over. Our findings demonstrate that up to a point, filings increase with age under each of the legislations. Labor force adjusted rates for each age group would be helpful in judging whether the number of charges for people in the protected groups truly "drop off" at a certain age, or whether, as we believe, the drop off in charges is due to older workers (particularly older disabled workers) leaving the workforce as they age. In our regression analysis comparing the decision to file under the ADA or jointly under the ADA/ADEA for those protected by both legislations (i.e., those who are disabled and 40 and over), the likelihood of feeling "doubly" discriminated against (perceiving age and disability discrimination) increases with each subsequent age group.
Reducing Discrimination Charges: Workplace Accommodation

As the average age of the workforce rises, workers with impairments and functional limitations will comprise a larger percentage of our workforce; the incidence, severity, and duration of disability is likely to also increase. In order to address the issues that face this increasing number of vulnerable workers, it will become increasingly important to identify proven strategies for encouraging employees to return to a productive role at work as soon as is reasonable. Workplace accommodations can be low cost and effective, allowing workers to be more productive [40]. However, commonly provided workplace accommodations often target younger employees, while older employees may not receive the accommodation that they need to be productive-for example, $50 \%$ of older adults report no accommodations for visual impairments [41]. When a limiting condition is attributed to age, individuals may be less likely to recognize the need for accommodation, and even when the need for accommodation is acknowledged, they are less likely to have their need met [42]. Other research suggests that workplaces may be ill-equipped to respond to needs of the aging and disabled population. A survey of human 
Table 3 Logit analysis of jointly-filed ADA/ADEA charges
The odds ratios are calculated by exponentiating the logit coefficients: $\mathrm{e}^{\delta}$. Holding other variables in the model at fixed values, the ratios reveal the odds of jointly-filing ADA/ADEA charges of discrimination for people with the characteristic $\delta$ as compared with those in the reference group. To interpret the odds ratios in terms of percent change, subtract one from this number: $\mathrm{e}^{\delta}-1$

$* P<0.05$; ** $P<0.01$; note reference categories are in parentheses

\begin{tabular}{|c|c|c|c|}
\hline & \multirow[t]{2}{*}{ Odds ratio } & \multicolumn{2}{|c|}{ 95\% Confidence interval } \\
\hline & & Lower limit & Upper limit \\
\hline \multicolumn{4}{|l|}{ Age $(40-44)$} \\
\hline $45-49$ & $2.152 * *$ & 2.079 & 2.228 \\
\hline $50-54$ & $4.523^{* *}$ & 4.371 & 4.679 \\
\hline $55-59$ & $7.759 * *$ & 7.483 & 8.045 \\
\hline $60-64$ & $14.082 * *$ & 13.478 & 14.714 \\
\hline $65-69$ & $18.500^{* *}$ & 17.275 & 19.812 \\
\hline $70+$ & $22.336^{* *}$ & 20.472 & 24.370 \\
\hline Missing & $0.091 * *$ & 0.086 & 0.097 \\
\hline \multicolumn{4}{|l|}{ Gender (Female) } \\
\hline Male & $1.076^{* *}$ & 1.053 & 1.099 \\
\hline Missing gender & $1.884 * *$ & 1.754 & 2.024 \\
\hline \multicolumn{4}{|l|}{ Race (White) } \\
\hline Nonwhite & $1.353 * *$ & 1.321 & 1.387 \\
\hline Missing race & $1.661 * *$ & 1.596 & 1.728 \\
\hline \multicolumn{4}{|l|}{ Issue } \\
\hline Termination & $2.055^{* *}$ & 2.003 & 2.108 \\
\hline Reasonable accommodation & $0.482 * *$ & 0.470 & 0.495 \\
\hline Terms/conditions & $1.873^{* *}$ & 1.823 & 1.924 \\
\hline Harassment & $2.167 * *$ & 2.098 & 2.237 \\
\hline Hiring & $2.050 * *$ & 1.967 & 2.136 \\
\hline Discipline & $1.568 * *$ & 1.499 & 1.641 \\
\hline Promotion & $3.613 * *$ & 3.421 & 3.815 \\
\hline Demotion & $2.200 * *$ & 2.077 & 2.330 \\
\hline Wages & $1.851^{* *}$ & 1.746 & 1.963 \\
\hline \multicolumn{4}{|l|}{ Industry (Manufacturing) } \\
\hline Agriculture, forestry, fishing & 1.054 & 0.919 & 1.209 \\
\hline Mining & $1.263 * *$ & 1.096 & 1.455 \\
\hline Construction & 0.970 & 0.894 & 1.053 \\
\hline Trans., Comm., Elec., gas, and sanitary & 1.011 & 0.962 & 1.062 \\
\hline Wholesale trade & 1.052 & 0.967 & 1.145 \\
\hline Retail trade & 0.997 & 0.957 & 1.039 \\
\hline FIRE & 1.032 & 0.977 & 1.090 \\
\hline Services & 0.996 & 0.962 & 1.031 \\
\hline Public administration & 0.962 & 0.918 & 1.009 \\
\hline Missing industry & $1.040^{*}$ & 1.003 & 1.079 \\
\hline \multicolumn{4}{|l|}{ Number of employees ( $<15$ employees) } \\
\hline 15-100 employees & $0.623 * *$ & 0.512 & 0.759 \\
\hline 101-200 employees & $0.616^{* *}$ & 0.505 & 0.751 \\
\hline 201-500 employees & $0.679 * *$ & 0.557 & 0.828 \\
\hline $500+$ employees & $0.701 * *$ & 0.576 & 0.853 \\
\hline Missing number of employees & $0.444 * *$ & 0.365 & 0.540 \\
\hline \multicolumn{4}{|l|}{ Geographic region (East South Central) } \\
\hline New England & $1.452 * *$ & 1.352 & 1.559 \\
\hline Middle Atlantic & $1.258^{* *}$ & 1.192 & 1.328 \\
\hline East North Central & $1.313 * *$ & 1.249 & 1.381 \\
\hline West North Central & $1.140 * *$ & 1.079 & 1.205 \\
\hline South Atlantic & $0.911 * *$ & 0.866 & 0.958 \\
\hline West South Central & $1.146^{* *}$ & 1.086 & 1.210 \\
\hline Mountain & $0.892 * *$ & 0.844 & 0.943 \\
\hline Pacific & $0.723 * *$ & 0.685 & 0.763 \\
\hline
\end{tabular}


resource professionals discovered that employers were much less familiar with accommodations for visual and hearing impairments than for other types of disabilities, felt such accommodations were more difficult to make, and had made such accommodations much less frequently [33]. Since loss of visual and hearing acuity is more common in older workers, this lack of experience in making accommodations lessens the likelihood that employers are prepared to deal with these needed accommodations.

The high prevalence of charges relating to reasonable accommodation under the ADA (27\% of all charges) and ADEA/ADA filed jointly (17\% of all charges) suggests that closer attention to this process is needed within workplaces. Research reveals that when a return-to-work or disability management program is in place, human resource professionals report it contributes to compliance with antidiscrimination legislation by raising supervisor awareness, creating an organizational structure for accommodations, and raising acceptance of employees with disabilities within the organization [33]. All these can create a positive workplace culture that supports the retention of older workers, as well as those with disabilities.

Employers will be better able to accommodate individuals who are able to express their accommodation needs, so workers need to be informed about their rights regarding accommodation and coached in appropriate ways to approach an employer to request accommodation. Replacing experienced workers is a costly alternative. These employees have distinct performance advantages, particularly in roles that require advanced skills, training, and knowledge of the company's business processes, people or customers [43]. Age-related changes in physical and cognitive abilities can raise adaptive challenges for older working adults, but with optimal person-environment fit and attention to the increased variability to be expected among older employees, many can continue to work safely and successfully. Providing accommodations tailored to the individual also reduces the likelihood of such workers leaving the workplace and migrating to long-term disability benefits [44].

There is a great deal of variability in the needs of older workers, in terms of type of disability and needed accommodation. However, the relatively high prevalence of certain conditions (and charges) can provide useful information to employers who would like to create a more accommodating workplace for aging and disabled workers. Analysis of ADA and joint ADA/ADEA charges demonstrates that many of the most common bases of discrimination charges are similar across these two protected groups (see Fig. 3). Among older workers who filed joint ADA/ADEA charges, orthopedic/structural back impairment, nonparalytic orthopedic impairment and heart conditions were the most commonly-cited bases. Heart conditions, diabetes and cancer are more common bases among the joint filers as compared with ADA single filers, likely because these conditions are more common among older people protected under the ADEA.

With special attention to the more common conditions (and common bases for complaints) among older workers, employers can be more proactive regarding interventions and/or accommodations for particular conditions. A ready example might be doing an ergonomic assessment in positions requiring heavy lifting, where there is an aging worker cohort and therefore a higher likelihood of orthopedic or musculoskeletal injury. Company wellness programs might include classes related to nutritional, exercise and other life styles changes to lower the risk of heart disease. Employee Assistance Programs can highlight classes and support services for depression, perhaps targeting the issues of older workers. Introducing or heightening awareness of existing flex-time and flex-place policies may also afford older workers and those with disabilities needed policy modifications around time and attendance that may facilitate retention by accommodating specific needs presented by particular health conditions.

Reducing Discrimination Charges: Improving Workplace Policies and Practices

Roughly $60-70 \%$ of charges filed under the ADA and/or ADEA cite a termination-related issue. This suggests that employer policies and practices to date are not adequately structured to successfully keep disabled and older workers on the payroll; clearly, these workers feel pushed out before they are ready to leave voluntarily. Despite the encouragement of the AARP to have businesses double retention to $40 \%$ of experienced workers, firms demonstrate a preference for hiring from outside labor sources [43]. Employers may have incentives operating to encourage workers to make this exit from the workforce, including concerns about rising health care costs. "For HR professionals, the most significant issue relating to an aging population is the potential increase in health care costs that is expected to accompany the growth in the proportion of older Americans" [45, p. 13]. Since most of these employees are covered by their employer's health insurance, employers fear that the consequences of retaining a significant number of older workers will have severe economic repercussions. Alternative health care plans that afford workers adequate coverage through state plans with greater pooled risk might be an attractive option for employers.

Another potential underlying cause for these forced separations may be a perceived mismatch between needed worker skill sets and the performance readiness of these workers. Targeted workplace training and development efforts may assist in heightening the likelihood that senior workers will receive requisite updates to skills and new 
processes. An added state or local government strategy that would be of assistance is to offer incentives simultaneously to employees for upgrading job skills and to employers who provide such opportunities [31]. These would also offer incentives to educational institutions for providing programs that help employees to upgrade job skills.

While the EEOC data are rich, it is unfortunate that they do not contain supplemental information regarding a secondary cause for each filed allegation. As such, we are also unable to speculate as to the roles that flexible work hours, flex-place alternatives, design performance management, and reward systems might have had in reducing the perception of discrimination. These practices, which include adopting new management styles and work setting protocols that focus on an age-diverse workforce [14], are embedded in an array of human resources approaches. While companies are recognizing that a maturing workforce can positively impact customer satisfaction and profitability, effective intergenerational inclusion initiatives may need further development [7].

The high incidence of perceived retaliation among the EEOC charges (cited as a basis in between 7 and $15 \%$ of ADA and/or ADEA charges) further points to the importance of a closer examination of workplace culture and perceptions of older workers and those with disabilities. A culture that allows for age or disability discrimination will prevent senior workers and those with disabilities from reaching their full potential. All workplace environments are maximized by a climate of inclusion and flexibility. Organizations with cultures of trust and inclusion allow for healthy and open dialogue, placing them in a better position to plan and control outcomes. Successful companies will make it a priority to create a workplace culture that embraces and encourages diversity. This has been successfully done for race, sex, and sexual orientation. Now age and disability must be added to that list.

Acknowledgments The authors would like to acknowledge Sara Van Looy's (EDI Research and Administrative Assistant) assistance in the preparation of this manuscript, and the contributions to earlier versions of this manuscript provided by the following individuals: Daniel Kohrman, American Association of Retired Persons; Charlotte Lanvers, Disability Rights and Education Defense Fund; Ronald Edwards, Christopher Kuczynski, and Peggy Mastroianni, U.S. EEOC; David Keer, U.S. Department of Education, National Institute on Disability and Rehabilitation Research; and Lisa Nishii and Ariel Avgar, Cornell University.

Open Access This article is distributed under the terms of the Creative Commons Attribution Noncommercial License which permits any noncommercial use, distribution, and reproduction in any medium, provided the original author(s) and source are credited.

\section{Appendix}

See Tables 4 and 5 .

Table 4 Percentage of charges filed by issue and statute, averaged over 1993-2007

\begin{tabular}{|c|c|c|c|c|c|}
\hline \multirow[t]{2}{*}{ Issues } & \multicolumn{2}{|l|}{$\mathrm{ADA}$} & \multicolumn{2}{|l|}{ ADEA } & \multirow{2}{*}{$\begin{array}{l}\text { ADA/ADEA } \\
\text { Filed Jointly }\end{array}$} \\
\hline & Filed alone or jointly & Filed alone & Filed alone or jointly & Filed Alone & \\
\hline Discharge & 55.30 & 55.72 & 49.44 & 48.72 & 55.68 \\
\hline Reasonable accommodation & 24.64 & 26.93 & 0.07 & - & 17.38 \\
\hline Terms/conditions & 18.78 & 15.61 & 18.15 & 13.82 & 21.88 \\
\hline Harassment & 12.18 & 8.84 & 11.06 & 6.86 & 14.86 \\
\hline Hiring & 8.16 & 9.12 & 13.04 & 15.54 & 8.80 \\
\hline Other & 6.00 & 5.30 & 4.23 & 3.31 & 5.87 \\
\hline Discipline & 5.19 & 4.10 & 4.97 & 3.47 & 6.13 \\
\hline Constructive discharge & 3.70 & 3.48 & 3.63 & 3.10 & 3.68 \\
\hline Promotion & 3.47 & 2.38 & 8.18 & 5.81 & 5.39 \\
\hline Layoff & 3.19 & 2.84 & 6.68 & 7.68 & 5.62 \\
\hline Wages & 3.00 & 2.10 & 5.20 & 3.91 & 4.29 \\
\hline Demotion & 2.77 & 2.27 & 4.25 & 3.61 & 4.32 \\
\hline Suspension & 2.38 & 2.05 & 1.94 & 1.31 & 2.39 \\
\hline Intimidation & 2.09 & 1.46 & 1.89 & 1.14 & 2.64 \\
\hline Reinstatement & 2.06 & 2.27 & 0.62 & 0.46 & 1.69 \\
\hline Assignment & 1.93 & 1.58 & 2.04 & 1.56 & 2.54 \\
\hline Benefits & 1.74 & 1.56 & 1.95 & 2.17 & 2.13 \\
\hline Benefits-retirement/pension & 0.95 & 1.17 & 1.50 & 2.51 & 0.50 \\
\hline Retirement-involuntary & 0.85 & 0.85 & 2.19 & 3.08 & 1.67 \\
\hline Benefits-insurance & 0.84 & 0.86 & 0.42 & 0.45 & 0.84 \\
\hline
\end{tabular}


Table 4 continued

\begin{tabular}{|c|c|c|c|c|c|}
\hline \multirow[t]{2}{*}{ Issues } & \multicolumn{2}{|l|}{ ADA } & \multicolumn{2}{|l|}{ ADEA } & \multirow{2}{*}{$\begin{array}{l}\text { ADA/ADEA } \\
\text { Filed Jointly }\end{array}$} \\
\hline & Filed alone or jointly & Filed alone & Filed alone or jointly & Filed Alone & \\
\hline Recall & 0.79 & 0.79 & 0.87 & 0.94 & 1.02 \\
\hline Training & 0.78 & 0.58 & 1.21 & 0.88 & 1.10 \\
\hline Prohibited medical inquiry/exam & 0.67 & 0.52 & - & - & 0.69 \\
\hline Union representation & 0.52 & 0.48 & 0.51 & 0.49 & 0.58 \\
\hline Breach of confidentiality & 0.40 & 0.35 & - & - & 0.30 \\
\hline References unfavorable & 0.27 & 0.28 & 0.18 & 0.13 & 0.25 \\
\hline Job classification & 0.27 & 0.23 & 0.35 & 0.26 & 0.38 \\
\hline Qualifications & 0.24 & 0.18 & 0.35 & 0.25 & 0.36 \\
\hline Exclusion & 0.21 & 0.20 & 0.21 & 0.15 & 0.22 \\
\hline Referral & 0.16 & 0.18 & 0.14 & 0.13 & 0.15 \\
\hline Seniority & 0.16 & 0.12 & 0.21 & 1.54 & 0.18 \\
\hline Maternity & 0.15 & 0.03 & - & - & - \\
\hline Testing & 0.14 & 0.13 & 0.15 & 0.10 & 0.22 \\
\hline Segregated facilities & 0.11 & 0.16 & 1.00 & - & 0.33 \\
\hline Waivers & 0.10 & 0.05 & 0.23 & 0.27 & 0.37 \\
\hline Tenure & 0.07 & 0.05 & 0.12 & 0.09 & 0.14 \\
\hline Severance pay denied & 0.07 & 0.05 & 0.07 & 0.25 & - \\
\hline Early retirement incentive & 0.03 & 0.03 & 0.28 & 0.45 & 0.19 \\
\hline Posting notices & 0.03 & 0.03 & 0.03 & 0.04 & - \\
\hline Apprenticeship & 0.02 & 0.03 & 0.04 & 0.06 & - \\
\hline Advertising & 0.02 & 0.03 & 0.12 & 0.24 & - \\
\hline
\end{tabular}

Source: Calculations by Cornell University, Employment and Disability Institute, using the EEOC IMS files, 1993-2007

Note these columns do not sum to 100 as more that one issue may be cited for each charge. A dash indicates that all cell sizes used to construct the average contain five or fewer observations. To protect data confidentiality, this information is suppressed

Table 5 Percentage of charges filed by ADA basis and statute, 1993-2007 average

\begin{tabular}{llrr}
\hline ADA basis & ADA & & ADA/ADEA \\
\cline { 2 - 4 } & Filed Alone or Jointly & Filed Alone & Filed Jointly \\
\hline Other disability & 25.93 & 24.84 & 26.69 \\
Retaliation & 13.11 & 7.64 & 17.34 \\
Orthopedic/structural back impairment & 12.23 & 12.63 & 11.09 \\
Regarded as disabled & 9.86 & 9.62 & 11.72 \\
Nonparalytic orthopedic impairment & 7.54 & 7.41 & 8.91 \\
Depression & 5.75 & 5.80 & 4.86 \\
Diabetes & 3.75 & 3.59 & 5.05 \\
Other psychiatric disorders & 3.62 & 3.82 & 2.50 \\
Heart/cardiovascular & 3.57 & 2.91 & 8.25 \\
Hearing impairment & 2.99 & 3.30 & 2.99 \\
Record of disability & 2.92 & 2.97 & 3.46 \\
Other & 2.86 & 2.26 & 3.26 \\
Other neurological & 2.67 & 2.93 & 2.22 \\
Cancer & 2.43 & 2.26 & 4.10 \\
Other anxiety disorder & 2.36 & 2.37 & 1.95 \\
Vision impairment & 2.28 & 2.49 & 2.23 \\
Missing digits/limbs & 1.88 & 2.23 & 1.20 \\
\hline
\end{tabular}


Table 5 continued

\begin{tabular}{|c|c|c|c|}
\hline \multirow[t]{2}{*}{ ADA basis } & \multicolumn{2}{|l|}{ ADA } & \multirow{2}{*}{$\begin{array}{l}\text { ADA/ADEA } \\
\text { Filed Jointly }\end{array}$} \\
\hline & Filed Alone or Jointly & Filed Alone & \\
\hline Manic depression (bi-polar) & 1.78 & 2.07 & 0.92 \\
\hline Epilepsy & 1.62 & 2.00 & 0.55 \\
\hline Learning disability & 1.58 & 1.83 & 0.71 \\
\hline Asthma & 1.55 & 1.57 & 1.31 \\
\hline Handicap (not ADA) & 1.40 & 1.35 & 1.80 \\
\hline Alcoholism & 1.34 & 1.46 & 0.99 \\
\hline HIV & 1.34 & 1.68 & 0.21 \\
\hline Multiple sclerosis & 1.18 & 1.43 & 0.68 \\
\hline Blood (other) & 1.08 & 1.17 & 0.88 \\
\hline Gastrointestinal & 0.91 & 0.95 & 0.80 \\
\hline Relationship/association & 0.85 & 0.76 & 1.03 \\
\hline Cumulative trauma disorder & 0.84 & 0.86 & 0.68 \\
\hline Other pulmo/respiratory & 0.80 & 0.81 & 0.98 \\
\hline Paralysis & 0.77 & 0.87 & 0.53 \\
\hline Brain/head injury (traumatic) & 0.70 & 0.82 & 0.49 \\
\hline Drug addiction & 0.68 & 0.79 & 0.16 \\
\hline Post-traumatic stress disorder & 0.64 & 0.61 & 0.55 \\
\hline Speech impairment & 0.62 & 0.66 & 0.46 \\
\hline Mental retardation & 0.61 & 0.77 & 0.30 \\
\hline Kidney impairment & 0.60 & 0.64 & 0.51 \\
\hline Allergies & 0.57 & 0.61 & 0.46 \\
\hline Cerebral palsy & 0.44 & 0.57 & 0.16 \\
\hline Schizophrenia & 0.38 & 0.42 & 0.21 \\
\hline Chemical sensitivity & 0.27 & 0.32 & 0.22 \\
\hline Disfigurement & 0.24 & 0.25 & 0.21 \\
\hline Autism & 0.05 & 0.07 & - \\
\hline Tuberculosis & 0.04 & 0.05 & - \\
\hline Dwarfism & 0.04 & 0.05 & - \\
\hline Cystic fibrosis & 0.03 & 0.04 & - \\
\hline Genetic discrimination & 0.02 & 0.03 & - \\
\hline Alzheimer's & 0.02 & 0.03 & - \\
\hline
\end{tabular}

Source: Calculations by Cornell University, Employment and Disability Institute, using the EEOC IMS files, 1993-2007

Note these columns do not sum to 100 as more that one basis may be cited for each charge. A dash indicates that all cell sizes used to construct the average contain five or fewer observations. To protect data confidentiality, this information is suppressed

\section{References}

1. Toossi M. Employment outlook: 2006-16: labor force projections to 2016: more workers in their golden years. Mon Labor Rev. 2007;130(11):33-52.

2. Williams AH. How to manage your aging workforce. Brentwood: M. Lee Smith Publishers LLC; 2002.

3. He W, Sengupta M, Velkoff VA, DeBarros KA. 65+ in the United States: 2005. U.S. Department of the Census: current population reports. Washington DC: U.S. Government Printing Office; 2005.

4. Stock WA, Beegle K. Employment protections for older workers: do disability discrimination laws matter? Contemp Econ Policy. 2004;22(1):111-26.
5. U.S. Census Bureau. Facts for features: oldest baby boomers turn 60 ! [Internet]. 2006 [updated 2009 Apr 17; cited 2009, Jul 7]. Available at: http://www.census.gov/Press-Release/www/releases/archives/ facts_for_features_special_editions/006105.html.

6. Congressional Budget Office. Disability and retirement: the early exit of baby boomers from the labor force. Washington DC: The Congress of the United States, Congressional Budget Office; 2004.

7. Morton L, Foster L, Sedlar J. Managing the mature workforce. New York: The Conference Board; 2005.

8. Collison J. 2005 Future of the U.S. labor pool: survey report. Alexandria: Society for Human Resource Management; 2006.

9. Silverstein M. Meeting the challenges of an aging workforce. Am J Ind Med. 2008;51(4):269-80. 
10. Helman R, Copeland C, Van Derhei J. Will more of us be working forever? The 2006 retirement confidence survey. Issue brief. No. 292. Washington DC: Employee Benefits Research Institute; 2006.

11. Reynolds S, Ridley N, Van Horn CE, A work filled retirement: workers' changing views on employment and leisure. New Brunswick: Rutgers, the State University of New Jersey, John J. Heldrich Center for Workforce Development; 2005.

12. Rainville G. AARP Bulletin survey on employment status of the $45+$ population: executive summary [Internet]. 2009 [cited 2009 Jul 7]; Available at: http://www.aarp.org/research/work/ employment/bulletin_jobs_09.html.

13. Brooke L. Human resource costs and benefits of maintaining a mature-age workforce. Int J Manpower. 2003;24(3):260-83.

14. Card L, O'Donnell M. Ejection vs. retention: weighing the pros and cons of employing elders. In: MacIntosh B, editor. Aging and the workforce [Internet]. 2004 [cited 2009 Jun 8]. Available at: http://www.bsad.uvm.edu/Research/inProgress/Resources/Aging Emp/.

15. Canadian Centre for Occupational Health and Safety. OSH answers: aging workers [Internet]. 2002 [updated 2002, Jul 12; cited 2006 Mar 3]; Available at: http://www.ccohs.ca/oshanswers/ psychosocial/aging_workers.html.

16. Minter SG. Ergonomic challenge: the aging work force. Occup Hazards. 2002;64(9):6.

17. Biddle J, Boden LI, Reville RT. Older workers face more serious consequences from workplace injuries. Health and income security for an aging workforce briefs, no 5 . Washington DC: National Academy of Social Insurance; 2003.

18. Platt RK. The aging work force: angst for organizations, baby boomers. Workspan. 2001;44(1):26-9.

19. Akabas S, Gates L, Galvin D. Disability management: a complete system to reduce costs, increase productivity, meet employee needs, and ensure legal compliance. New York: AMACOM; 1992.

20. Shrey D, Hursh P, Gallina S, White A. Disability management best practices and joint labour-management collaboration. Int J Disabil Manag Res. 2006;1(1):52-63.

21. Erickson WA, Lee C. 2007 Disability status report: United States [Internet]. Ithaca, NY: Cornell University Rehabilitation Research and Training Center on Disability Demographics and Statistics; 2008 [cited 2009 Jul 7]. Available at: http://www. disabilitystatistics.org/.

22. Kaye HS. Stuck at the bottom rung: occupational characteristics of workers with disabilities. J Occup Rehabil. 2009;19(2):115-28.

23. Stapleton D, Burkhauser RV, editors. The decline in employment of people with disabilities: a policy puzzle. Kalamazoo: W.E. Upjohn Institute for Employment Research; 2003.

24. Bendick M Jr, LE Brown. No foot in the door: an experimental study of employment discrimination against older workers. J Aging Soc Policy. 1999;10(4):5-23.

25. Lahey JN. Do older workers face discrimination? Center for retirement research. Issue brief, no. 33. Boston: Boston College, Center for Retirement Research; 2005.

26. Goldman BM, Gutek BA, Stein JH, Lewis K. Employment discrimination in organizations: antecedents and consequences. J Manage. 2006;32(6):786-830.

27. Perry EL, Parlamis JD. Age and ageism in organizations: a review and consideration of national culture. In: Konrad AM, Prasad P, Pringle JK, editors. Handbook of workplace diversity. Thousand Oaks: Sage Publications; 2006.
28. Posthuma RA, Campion MA. Age stereotypes in the workplace: common stereotypes, moderators, and future research directions. J Manage. 2009;35(1):158-88.

29. Roscigno VJ, Mong S, Byron R, Tester G. Age discrimination, social closure and employment. Soc Forces. 2007;86(1):313-34.

30. Johnson RW, Neumark D. Age discrimination, job separations, and employment status of older workers: evidence from selfreports. National Bureau of Economic Research working paper series. No. 5619. Cambridge: National Bureau of Economic Research; 1996.

31. Schultz KS, Sirotnik BW, Bockman S. Plight of an aging workforce [Internet]. Research report funded by the California State University Faculty Research Fellows program for the California Assembly Speaker's Office of Member Services. 2000 [cited 2007 Sep 2]. Available at: http://www.csus.edu/calst/ Government_Affairs/reports/ffp36.pdf.

32. Stone-Romero EF, Stone DL, Lukaszewski K. The influence of disability on role-taking in organizations. In: Konrad AM, Prasad P, Pringle JK, editors. Handbook of workplace diversity. Thousand Oaks: Sage Publications; 2006.

33. Bruyere SM. Disability employment policies and practices in private and federal sector organizations [Internet]. Ithaca, NY: Cornell University, School of Industrial and Labor Relations, Program on Employment and Disability. 2000 [cited 2009 Jul 7]. Available at: http://digitalcommons.ilr.cornell.edu/edicollect/63/.

34. Bruyere SM, Erickson WA, VanLooy S. Comparative study of workplace policy and practices contributing to disability nondiscrimination. Rehabil Psychol. 2004;49(1):28-38.

35. Bruyère SM, Erickson WA, VanLooy SA. The impact of business size on employer ADA response. Rehabil Couns Bull. 2006;49(4): 194-206.

36. Rix S. Aging and work-a view from the United States. Washington DC: American Association of Retired Persons Public Policy Institute; 2004.

37. McMahon B, Shaw L, Jaet D. An empirical analysis: employment and disability from an ADA litigation perspective. NARPPS J. 1995;10(3):3-14.

38. Social Security Administration, Annual statistical report on the social security disability insurance program. Washington DC: Social Security Administration; 2007. SSA Publication No. 13-11826.

39. Margolis HS, Braun JA. Age discrimination in employment. Elder law portfolio series, no. 17. New York: Aspen Publishers; 2004.

40. Schartz HA, Hendricks DJ, Blanck P. Workplace accommodations: evidence based outcomes. Work. 2006;27(4):345-54.

41. Williams M, Sabata D, Zolna J. User needs evaluation of workplace accommodations. Work. 2006;27(4):355-62.

42. McMullian JA, Shuey KM. Ageing, disability and workplace accommodations. Ageing Soc. 2006;26:831-47.

43. Perrin T. The business case for workers age 50+: planning for tomorrow's talent needs in today's competitive environment [Internet]. Washington DC: American Association of Retired Persons; 2005 [cited 2009 Jul 7]. Available at: http://www.aarp. org/research/work/employment/workers_fifty_plus.html.

44. Burkhauser R, Butler J, Weathers RII. How policy variables influence the timing of social security disability insurance applications. Soc Secur Bull. 2002;64(1):52-83.

45. Schramm J. SHRM workplace forecast. Alexandria: Society for Human Resource Management; 2006. 